\title{
Disaster policy and climate change: how much more of the same?
}

Stephen Dovers and John Handmer

\subsection{Introduction}

Over recent decades, research and policy have steadily moved from viewing natural disasters as just that - 'natural', imposed on humans by outside forces - to understanding disasters as phenomena more often caused by the vulnerability of societies, settlements, and assets that are constructed or shaped by human decisions. Disasters are increasingly understood as something we have a strong degree of control over, through active policy choices or a failure to make choices. There has also been increasing understanding of the nature of disasters and of human vulnerability to them through strengthened research efforts and through better documentation of events and experiences: vulnerability to disasters, and thus disaster risk, grows with the size and spread of human settlements, and the value and exposure of built and other assets. More recently the prospect of climate change, and specifically an increased frequency and intensity of severe climatic events, has accelerated reconsideration of disasters and how society should or could deal with them.

This chapter examines ways in which disasters have been understood and responded to over time, from a policy and institutional perspective. The central question raised in the chapter is the degree to which current policy approaches and institutional capacities are sufficient for the future. Is a further incremental evolution of policy, such as has occurred over recent decades, enough? How much will the future be more of the same? The chapter extracts major themes from the disaster literature (e.g., Handmer and Dovers, 2013) and brings these into a closer consideration of the interplay between 'traditional' disaster thinking and a future where climate change is proposed to have a significant impact on disasters (e.g., IPCC, 2012).

We first summarise major trends in disaster policy and emergency management over recent decades, and then consider the implications of climate change for this already changed and changing agenda. We consider possible future implications, and advance the prospect of deeper integration of disaster policy across other policy sectors ('mainstreaming'), within the broader agenda of sustainable development.

We start with a note on the terminology used in this chapter, as the use of terms varies considerably across countries, disciplines, and agencies. Disasters here are considered to be larger scale events (whether of natural cause or not) which overwhelm capacities. Disaster policy (and related, broader institutional settings) comprises the higher level, strategic settings within which societies understand and respond to disaster events. Emergency management refers to the practical end of disaster response, expressed in specific agencies, practices, and processes to attend to more regular and tractable emergency situations (e.g. regular floods, industrial accidents, expected cyclones, etc.) as well as rarer, more difficult large scale events. The international terms of disaster risk and disaster risk reduction (DRR) are within this definitional scope; however, we cover both the 'routine' or traditional emergency management end of the spectrum as well as the greater magnitude 'non-routine' or 'complex unbounded' disaster events (see further below). Increasing vulnerability to routine events and to serious disasters increases what is often termed 'disaster risk'. The teminology focuses attention on the central question here, which is the adequacy of current policy and institutional arrangements to cope with both existing and unpredictable but likely more demanding future situations.

\subsection{The evolution of disaster policy}

An extensive literature documents the overriding importance of human factors - social, economic, and political - in

Extreme Natural Hazards, Disaster Risks and Societal Implications, eds. Alik Ismail-Zadeh, Jaime Urrutia Fucugauchi, Andrzej Kijko, Kuniyoshi Takeuchi and Ilya Zaliapin. Published by Cambridge University Press. C Cambridge University Press 2014. 
generating the conditions that can lead to disasters, and to more expectable emergency situations, and that can exacerbate the impacts of natural phenomena (White, 1946; Turner, 1978; Perrow, 1984; Quarantelli, 1998, Mileti, 1999; Mitchell, 1999; Pelling, 2003). The central role of vulnerability created by settlement, political, and economic circumstances has been increasingly understood. Also, it is increasingly recognised that human impacts on the Earth are changing global rather than local natural systems: the vulnerability of societies and communities is not influenced only by local or national decisions, but by global conditions and changes in social, technological, informational, and economic forces. Natural phenomena, in contrast, over which we have little or no direct control may make relatively modest contributions to disaster impacts: the risk of a disaster (in terms of impacts) occurring may be higher due to increased vulnerability even when no change has taken place in the frequency or intensity of natural phenomena (IPCC, 2012). This statement must be qualified for those whose livelihoods depend entirely upon enterprises closely influenced by climatic variability, and for exceptionally severe events such as the 2004 Asian tsunami, which may have very serious impacts at the local level, especially in poor countries and poor regions of otherwise wealthy countries. The European heatwaves of 2003, 2007, and 2010, the 2011 Japanese earthquake and tsunami, as well as Hurricane Katrina in New Orleans, highlight that rich countries also suffer extreme impacts.

In disaster and emergency management research and increasingly in policy, thinking has shifted from being dominated by a passive approach - accepting disasters as 'acts of God' - with the matching attitude that there is little that humans can do, to a more proactive approach that accepts the role of humans in creating vulnerability. This invites a greater focus on the purposeful development of institutions, policies, and emergency management practice aimed at reducing vulnerability and enhancing resilience, rather than simply responding to events. If the conditions for vulnerability to disasters are often in large part created by human choices (such as to settle or build in particular places, in a particular manner), then it is human choices that can address the situation. This is consistent with a broader theme in discourses of sustainable development: human culture, through its institutions, governance, and patterns of production and consumption, has created situations that are socially, environmentally, and/or economically unsustainable (Boyden, 1987). It follows that it is only through human culture (i.e. institutional etc. change) that greater sustainability can be pursued.

Disasters can result from an extreme event from nature triggering destruction and disruption to people and economies. This is our normal view of disaster, but extreme events do not necessarily result in disasters and disasters, in terms of impacts on humans, do not need extreme events, natural or otherwise. It is the impact on communities, economies, and ecosystems that defines a disaster, not the size of the natural event. Disasters frequently result from minor natural events, or some sequence of minor events, intersecting with susceptible human systems, resulting in major losses in the absence of major natural events. The capacity of a society or community to withstand and recover may be eroded over time through the cumulative impacts of a series of relatively minor or 'routine' events, such as a number of moderate floods occurring with greater than usual frequency. Furthermore, a gradual change in 'normal' conditions may also result in major impacts, for example thawing permafrost in the far northern hemisphere resulting in very severe damage to buildings and all types of infrastructure, or slow trends in atmospheric warming that gradually exceed the adaptive capacity of cropping systems. Human agency combines with natural variability to define each disaster event. Climate change, discussed below, may shift the frequency and intensity of some natural disturbances from 'routine' matters currently handled competently to a more difficult level. For example, there has been a shift in drought policy in a number of countries from treating drought as an exceptional occurrence requiring emergency assistance to policy settings to encourage landholder risk management (Cockfield and Dovers, 2013). Significant increases in drought occurrence would place such policy regimes under considerable pressure.

The shift in approach summarised above is a more positive perspective on disasters than the view that they were imposed on populations who were simply victims, where human intelligence and agency can be actively tumed towards making people and their settlements safer and more sustainable. However, recognising the importance of human agency may also encourage attribution of blame, whether deserved or not, so the shift is not entirely positive. It is certainly the case that changes in political attitudes and the extension of media and communications capacity have seen the search for 'those responsible' begin almost as soon as a disaster event unfolds. A search for lessons and better ways of doing things after an event is of course worthwhile, but sensationalised, short term media excitement is usually less than productive. An issue arising from this situation, not dealt with further here, is the most appropriate form of post-disaster inquiry that can yield positive lessons for the future as well as, if necessary, reveal negligence or culpability.

Modern emergency management is a well-established system of regulations, capacities, and agencies involving many actors, all with particular backgrounds and reasons for involvement. Often, key organisations have their 
origins in the 'civil defence' or 'home guard' capacities developed during World War II, which later evolved towards domestic threats rather than external military ones. Working with the career uniformed services and established welfare groups, such as the Red Cross and the Salvation Army, they supported the home front. The Cold War and the possibility of nuclear attack legitimised the maintenance of civil defence. These war-related organisations found themselves increasingly busy with everyday events and crises arising from natural agents and from industrial, transport, and technological failures. These events affected and concerned many more people than actual or possible military or security risks. During the 1970 s, most civil defence organisations in developed countries shifted focus to an emergency management, rather than war-related, emphasis and in doing so went from a focus solely on consequences to a more comprehensive approach that included prevention as well as response. Interestingly, there has been in recent years a rejoining of military and disaster/ humanitarian concerns, with military resources being utilised more often to support post-disaster response and recovery (but very rarely prevention and preparedness).

It is easy to see emergency management only in terms of obvious, visible tasks of response and the short term thinking that informs this. However, we need to be aware that the key groups include many dedicated more to recovery and support than the immediate task of short term response. This is especially the case in the nongovermmental and government welfare sector, who may act quickly but whose work extends much longer after an event, assisting communities and individuals. We are not critical of a strong response focus - that is what society, media, and politicians want when a crisis erupts, and not to respond when lives and communities are at risk would be morally and politically unacceptable. However, we argue that a much greater emphasis on strategic policy is needed to increase the focus on prevention through tackling exposure and vulnerability, while maintaining a high level of response capability. The imperative of adapting to climate change is in keeping with this position, as it stretches thinking forward in time.

A schema representing these trends in emergency management is presented in Table 27.1. We argue that these trends, which have been largely evolutionary and incremental, not only need to continue but to intensify. The progress of the trends and changes varies by jurisdiction, by sector, and by particular agencies: in some cases the changes have been swift, in others slow and progressive, in others less noticeable. Thus the rate of change and reform needed varies also, from consolidation and extension of recent reforms to considerable efforts in a short time. In general, the trends have been evident from the post-WWII period, intensifying in the last two decades.

Table 27.1. Trends in emergency management (Handmer and Dovers, 2013)

\begin{tabular}{|c|c|}
\hline From & To \\
\hline \multicolumn{2}{|l|}{ Broad framing of the basic issue: } \\
\hline Disasters as 'other' or 'acts of God' & Disasters as generated by humans \\
\hline Event driven & Situational and less visible creeping hazards included \\
\hline \multicolumn{2}{|l|}{ Policy context: } \\
\hline \multirow[t]{3}{*}{ Lack of visibility and profile } & Legal liability \\
\hline & Rising expectations and critical scrutiny \\
\hline & Impacts of counter-terrorism and security \\
\hline \multicolumn{2}{|l|}{ Problem ownership and framing: } \\
\hline Acceptance/individual decision-making & Community vulnerability and sustainability \\
\hline Owned by government & Should be shared with those at risk \\
\hline Local & Local-global \\
\hline Choice & Institutional constraints \\
\hline \multicolumn{2}{|l|}{ Style: } \\
\hline Secret & Open \\
\hline Paramilitary & Dominantly civilian \\
\hline Uncertainty ignored or treated as quantifiable & Uncertainty is acknowledged \\
\hline \multicolumn{2}{|l|}{ Policy emphasis: } \\
\hline Accept or reduce loss & Manage vulnerability or increase resilience \\
\hline Focus on the hazard and event & Focus on community safety and consequences \\
\hline Solutions as separate & Solutions found in organization of society and the development process \\
\hline Based on direct emergency management experience & Based on evidence, and whole of society priorities \\
\hline
\end{tabular}


To help shift the sector away from a sole focus on response, the concept of a comprehensive approach was formalised in the early 1980s in Australia and the USA via the framework of 'PPRR': prevention, preparation, response, and recovery. This was to emphasise the need to deal with all aspects of regular emergency management not just response - and the importance of the overall state of vulnerability or resilience of societies and communities. Internationally, increased attention to communities' and nations' vulnerability to disaster is consistent with this shifting national focus, and led to the goal of DRR - a more proactive stance. In many countries and within international aid and development agencies, disasters and development were increasingly seen as closely linked (Cuny, 1983). The severe social and economic impacts of disasters can undermine the development process, setting countries back years, and poor human development is a major determinant of vulnerability to disasters. As a result, the concept and policy goal of DRR is often seen as a key part of development, a link recognised through a series of international meetings and agreements (e.g. at the World Summit on Sustainable Development in 2002, see further below).

A significant attempt to broaden the approach to emergency management has been through the introduction of a risk-based framework and approach, known in Australia and New Zealand as emergency risk management (ERM), based on the generic Australian-New Zealand Risk Management Standard (Standards Australia, 2004), now incorporated into an international standard (ISO31000: 2009). This approach offers a broader view of risk and the required response by spreading attention away from the event itself to include more explicit consideration of the socio-economic and environmental context of the risk, clear identification of what is at risk, what creates the risk, how that risk might be ameliorated, and monitoring and learning from the risk management experience.

This all highlights the desirability of emergency management or DRR serving a number of aims - with enough flexibility to cope with shifts in community and political prionities: to contribute to the aims of human development and economic stability. However, by themselves risk based approaches and PPRR support this aim, but do not achieve it. Achievement means viewing disasters as a policy and societal problem as much more than a matter for emergency managers only, but as a matter that is a whole-of-government and indeed whole-of-society concern. Addressing the preconditions of vulnerability to disasters requires attention by a wide range of policy sectors, agencies, and communities of interest. The event is the result of social and economic conditions and they may threaten our sustainability, and to that extent are issues of human and national security. A major challenge in disaster and emergency management is 'mainstreaming' disasters to ensure that the necessary actions are taken as a matter of course by policy agencies and actors across health, transport, communications, energy supply, water and sanitation, defence, land use planning, and more.

In summary, current trends in disaster research and management reflect a range of interests, some of them common to other public policy areas, such as climate change adaptation and sustainable development:

- seeking to put emergency management into the policy mainstream and away from a marginal or specialist activity by reframing problems;

- seeking to deal with causes rather than symptoms, emphasising the need for leaming and greater efforts in strategic policy development;

- the need for appropriate institutional structures to deliver long-term solutions;

- sharing ownership of the problem, and responsibility for solutions, with those at risk and working to reduce vulnerability.

Among many in the social and policy sciences, learning to live with hazards and sustainable development have come to be seen as interlocking aims (Mileti, 1999). The World Summit on Sustainable Development (WSSD), the ten year follow-on to the first United Nations Conference on Environment and Development (UNCED) of 1992, was held in 2002 in Johannesburg. The summit made disaster reduction one of its central themes. To be very vulnerable is not sustainable - economically, environmentally, or socially.

\subsection{Beyond 'natural' disasters}

Disaster and emergency management is now expected to operate at the front line of climate change adaptation. The impacts of climate change are predicted to manifest in more frequent and severe extreme climate and weather events, and these are already a major contributor to disasters. However, it is not only extreme climate and weather that are of concern, and care is needed in drawing climate change and disaster research policy and practice together so as not to begin to ignore non-climate related events (technological and industrial failures, pandemics, etc.). Here, we are interested primarily in the impacts or consequences on human systems of unexpected events (climate driven, non-climate driven, and various combinations).

To the extent that climate change is expressed through extreme weather and climate, it falls to emergency management to plan and prepare for the possibilities of additional and different extremes, and to respond and deal with the consequences. This is, in principle, the usual 
business of emergency management. The expectation that emergency management is to play a major role in adaptation to climate change is new. This is evident in the attention the area is attracting internationally, particularly through the Intergovernmental Panel on Climate Change SREX (Special Report on Extremes) reports (IPCC, 2011; 2012), and nationally such as through Australia's National Climate Change Adaptation Research Facility (NCCARF) programme, an activity which in different forms is replicated in many countries.

A key policy question is to what extent government should be involved in leading climate adaptation, whether directly or through enabling and supporting nongovernment actors and the private sector. The Australian Productivity Commission's draft report on Barriers to Effective Climate Change Adaptation provides an illustration of arguments around this question (Productivity Commission, 2012). This report is written from a traditional economic perspective, which would be expected to argue against a role for government and an enhanced role for the market. The report does this and downplays the need for government involvement in climate change adaptation. However, the Commission made an important exception - emergency management - where it argued for a major role for government. One reason economists and governments emphasise emergency management is that many emergency management measures are no- or lowregrets approaches. That is, if the changes in climate and weather turn out to be less problematic than predicted, the efforts are not wasted as managing existing risks and vulnerabilities better is in most cases desirable.

Through attention to climate change, disasters are being recast as a security issue of national and international strategic importance, a position more prominent on policy agendas than ever before. Note, however, that the impacts of climate change include more than only climate-driven disasters, but also reductions in water availability or agricultural yield and so on.

The Stern Review (Stern et al., 2006) argues that society has to act now or face 'devastating' economic consequences arising from climate change. On 17 April 2007 the UK put climate change on the agenda of the UN Security Council arguing that it threatened global security. This was not supported by all Security Council members, but follows a number of reports carrying similar warnings. In a similar vein, Australia's National Strategy for Disaster Resilience (Australia, 2011) asserts that 'climate change represents a most fundamental security challenge'. Such reports and commentary are strongest on the changes reflected in technical climate measurements, the causes of change, and future possibilities. However, for many people, such as those living in arctic, sub-arctic, and permafrost regions, changes to their environments have already been dramatic (CIEL 2007; IPCC 2012), destroying infrastructure and homes, threatening livelihoods and in some cases the viability and existence of communities.

Changes or increased variability in the climate are an important part of the future, However, other trends may be just as or more important: widespread environmental and water contamination is likely in future, partly caused by disruption through weather events, but also simply and more predictably - from an expanding population and industrialisation that places more people closer to more hazardous industries and contaminants, and places people and built assets in locations made hazardous by natural phenomena, areas that may have previously been avoided.

It is trends in the exposure and vulnerability of people that are or should be firmly within the ambit of emergency management and climate change adaptation (IPCC, 2012). If they are not, emergency management will be confined to responding to emergencies of escalating scale and complexity without the necessary increased efforts to avoid exposure and risk. The work of emergency managers already largely involves addressing the results of either poor decisions or non-decisions by other policy sectors (e.g., land use planning, infrastructure development): the future may be defined by this role of cleaning up after others, or by a more active engagement with key trends so as to lessen the impacts of events in future.

Some of the key trends that will influence vulnerability to disasters in future include:

- Population increase, but more importantly the distribution of populations. Globally, there will be an increase in the number of people exposed to all types of hazards, with an increasing number living in hazardous locations with marginal livelihoods and therefore a scarcity of coping resources.

- Urbanisation, which creates intense concentrations of humans and economic activity, and an increased potential of impacts by most types of disaster events through greater impacts on more people. Conversely, though, there may at the same time be a greater capacity with urbanisation to plan and deal with disaster events precisely because of a concentration of resources.

- Armed and political conflict, which may be over resources, ethnic divisions, ideologies, or even without discernible reason. Conflict decreases resilience by devastating livelihoods, infrastructure, and sources of food and water, often forces mass displacement, and redirects resources from productive use to military and/or short term humanitarian crisis response. Conflict undermines emergency management, public health, communications, education, and agricultural 
development, and deflects attention away from strategic issues such as responding to longer term environmental change.

- Often associated with conflict, the breakdown of governance and institutions decreases the capacity for organised emergency management and undermines the resilience of economies and communities, whether through reduced capacity or rising corruption.

- Uncertainty, and the difficulty of policy action in the face of uncertainty, can paralyse decision-making. It appears that there is increasing uncertainty on many fronts, including climatic, economic, social values and expectations, and political and legal conditions, with the impact of economic uncertainty illustrated dramatically by the recent and ongoing (at the time of writing) global financial crisis.

- Inequity and uneven distribution of economic power which, in addition to the trends listed above, create more vulnerable groups within society through changing employment conditions, declining access to health care, and displacement for major development projects.

We can ask how well disaster policy and emergency management meets expectations already, without considering future exacerbations, and then ask whether it has the operational, policy, and institutional capacity to cope with likely greater demands in future. Taking a broad definition of emergency management to include all involved (government and non-government), we argue that it does extraordinarily well in many countries, notwithstanding that things at times go wrong even in countries with high levels of resources and capacities. The picture is varied, however, with much emphasis on and thus evaluation of success focused only on very visible events with high profile responses. Much less attention is given to other parts of emergency management function: to less visible disasters in poor regions, and to prevention, preparedness, long-term recovery, and forward looking climate change adaptation. Subtle or systemic development policies aimed at increasing the general resilience of the many poor communities that are most affected by regular climatic or other events that are in themselves not dramatic and do not make for good headlines in the current media and political environment. When such actions are taken with an eye to an uncertain future comprising multiple, uncertain threats to communities, the story is harder still to communicate.

Addressing prevention, and improving resilience or reducing vulnerability, often requires fundamental change in policy, land use, and the distribution of economic and other resources. That may challenge powerful interests and may disrupt the status quo, and is likely to be resisted. Failure to address this basic challenge of incorporating DRR into human and economic development in many parts of the world will certainly result in large losses of life, livelihoods, and economic assets and activity.

\subsection{Climate change and disaster policy}

Here, we accept the strong scientific consensus that human-induced climate change is already occurring, that the rate of change will increase in the absence of at present unsupported levels of action to reduce greenhouse gas emissions, and that climate change will lead to increasing frequency and intensity of climate-driven natural disturbances and events such as wildfires, floods, cyclones, storms, coastal inundations, and heatwaves (IPCC, 2011, 2012). Given that a large proportion of disaster events and the work of emergency management relate to climate variability and extreme climatic events, there is clear relevance to disaster policy and emergency management. In this context, there are two important implications for disasters that are considered here:

1. the ability to cope with likely but inherently uncertain increases in the frequency and intensity of climaterelated disaster and emergency events; and

2. a recasting of the policy agenda and discourse of disasters within the broader context of climate change adaptation, to avoid unconnected efforts that are maintained within separate agencies, portfolios, and disciplines.

(Note: climate change policy has two dimensions: mitigation (reducing greenhouse gas emissions), and adaptation (to future climate change and increased variability and to that already 'locked in' due to already increased greenhouse gases in the atmosphere). While disasters are relevant in discussions of mitigation, as a major forthcoming area of impact in the absence of policy action, there is not a direct policy link. This chapter deals with the far more directly relevant issue of adaptation.)

To frame thinking around the impact on disaster policy capacities in a changing climate, the following schema matches generalised prospects of global warming represented as a simple typology (Dovers, 2009), with three general categories of policy problems in disasters and emergency management (routine, non-routine, complex unbounded, from Handmer and Dovers (2013)). The degrees of warming are indicative only, and the schema illustrative and general, but note that the most common interpretation of the 1992 UN Framework Convention on Climate Change instruction to avoid 'dangerous' climate change is to keep global warming at less than $2{ }^{\circ} \mathrm{C}$ :

I. More of the same, 'routine disaster problems', roughly up to $2{ }^{\circ} \mathrm{C}$ warming. Not dissimilar from existing 
variability faced by societies in living memory and with which societies generally cope through existing emergency management capacities but could adapt better with known strategies. Some shift in the parameters of climate and climate-related events and impacts, perhaps increasing in frequency and magnitude, but within institutional and societal memory.

II. 'Non-routine disaster problems', roughly $2-4{ }^{\circ} \mathrm{C}$ warming. Significantly exacerbated climate variability and impacts: droughts, floods, cyclones, heatwaves, vector-bome diseases, etc. Not events and impacts outside the historical experience of standard emergency management or disaster response capacities, but very challenging to capacities and institutions, where societies face a distinctly different climate and variability and events intensify, but within limits that allow adaptation even if this is very difficult.

III. 'Complex, unbounded disaster problems', roughly $>4{ }^{\circ} \mathrm{C}$. Climate change and variability beyond individual human experience, institutional memory, and societal capacity, and well beyond the scope of existing disaster policy and emergency management capacities, threatening the production bases of economies, inundation of major coastal settlements, widespread health impacts, the integrity of ecosystems and biodiversity, and the stability of policy and institutional systems. A radically different operating environment for communities and societies.

This schema is illustrative, and the degrees of impact and ability to cope will vary from place to place and unevenly over time. Disasters may be non-routine in one place but routine in another, relative to previous experience and capacities. However, to encourage thinking about the relationship between disasters and climate change, such a simple schema is useful. Climate adaptation has received less and later attention than climate mitigation, and has particular attributes as a policy problem (Dovers and Hezri, 2010). Climate adaptation is a diffuse policy challenge, with few systemic or generalisable policy 'levers' that will consistently shape and guide responses over many, very different climatic, biophysical, and political contexts. Adaptation requires investment of resources in the near term, in the face of uncertainty regarding both the magnitude of risks and impacts and their precise location of occurrence, for benefits that will occur in future. A lack of clarity of division between public and private benefits, stretched scales of time and space, deep uncertainty, and scattered policy and property rights and responsibilities are attributes that create difficult policy problems (Dovers, 1997). Whether the issue is investing in housing stock rehabilitation against heatwaves, or foreshore protection against rising sea levels and storm surge, the political, personal, and business case for near term investment may be hard to make.

Justifying investment in climate adaptation measures is indeed difficult, and this difficulty is relevant to disasters. In climate science and projections, scientific standards of proof and evidence apply, and allow for a common language in debating uncertainty. In mitigation policy, a small range of systemic policy instruments - trading systems, carbon taxes, technology substitution, etc. - can be reasonably well modelled and the emissions reduction predicted. The situation with adaptation policy is very different in two ways. Predicting with any certainty the location or impact of a climatic event is almost impossible with the current state of down-scaled climate change models, so picking where to invest in adaptation measures is complex and will always be contested. The decision to invest in preventative measures in one place will, in a world of limited resources, generally imply that another place will not receive support: there are strong equity dimensions to adaptation actions.

Second, it is difficult to evidence or predict the efficacy of most adaptation measures. Will a levee be high and strong enough; will a warning system work; will a fire or cyclone awareness campaign change behaviours; will a strategic climate adaptation assessment process influence the final proposals emerging from an infrastructure agency; will a new building code to handle increased weather events be observed? And so on. The efficacy of many adaptation measures cannot really be predicted robustly.

It is evident in the adaptation literature, and in adaptation policy discussions, that too little attention has been paid to existing bodies of research and policy theory and practice. This includes relevant disciplines such as law, public policy, social psychology, and institutional design, and relevant areas of practice such as public health, environmental policy, and emergency management (Dovers and Hezri, 2010). Cross-disciplinary and cross-policy sector learning is a current and future task that can better inform both climate adaptation and disaster policy.

Under a future characterised by level II and especially level III in the schema above, it would be expected that institutional systems will struggle to cope. Our institutional systems are a product of the problems faced and knowledge held in the past: that is the nature of durable and influential institutions (Connor and Dovers, 2004). Climate variability and a frequency and intensity of climate disasters outside societal and institutional memory will inevitably challenge current understanding and capacity, and that challenge is intensified by the requirement to 'mainstream' both adaptation and disaster policy across sectors and portfolios that have given these little attention previously. Institutional change is a complex matter and 
the possibilities and imperatives vary greatly from country to country; however, coping with a significant increase in disaster risk, exacerbated by climate change, represents a sizable task of cultural and institutional change.

These complexities and difficulties affecting climate adaptation apply equally to disasters and emergency management, which is unsurprising as the prospect of more frequent and/or intense climate-driven disasters are central to climate adaptation. The two main implications for and avenues for progressing policy responses are similar and will be discussed now.

First is the argument for 'no-regrets' or at least lowregrets options. These are options that, even in the absence of projected human-induced climate change, offer social, environmental, or economic benefits for other reasons. No-regrets options exist for mitigation, such as energy efficiency for business cost reasons or national energy security, as well as a way to reduce greenhouse gas emissions. In adaptation, there are more abundant possibilities, some examples of which will suffice here. With the prospect of increased heatwaves, dwelling design and insulation also addresses economic efficiency (reduced electricity costs, thermal comfort, reduce heat-related mortality). Better connection of remnant fauna habitats already justified now to preserve biodiversity is made more pressing with the likelihood of shifting climates and the tolerance of wildlife species. Water efficiency improvements to cope with worse drought in future should yield agricultural production efficiencies, lessen infrastructure costs with reduced need for additional supply, and provide more water to river and wetland ecosystems. Better communications, housing, and livelihood opportunities for poor, remote communities are entirely justified in political and moral terms, and would reduce the vulnerability of these communities to the impacts of increased climate variability. This list is lengthy, but more broadly, if we do not cope well enough with disasters now - and there is considerable evidence that that is the case - then improving disaster policy and response may be now more justifiable than ever as we combine the existing arguments with those concerned with climate adaptation. Can we achieve level I on the schema above, and perhaps progress well into level II, on the basis of no- or lowregrets options, at least in many contexts?

If climate change eventuates at the lower end of the I-III scale above, then improvements in capacities to cope with disasters will mean that societies will be better placed to handle 'more of the same'. However, even without climate change, an increase in disaster impacts is almost certainly going to be experienced due to trends other than climate change noted above: increased capacity will be required climate change notwithstanding. Should climate change produce impacts in level III above, then that is well beyond more-of-the-same, and will require a vastly accelerated evolution of DRR capacities.

On no- or low-regrets options, while climate change adaptation benefits invite consideration of measures that would also achieve better preparedness for disasters that will doubtless occur climate change notwithstanding, there is another basis for no-regrets arguments for improving disaster preparedness capacities: human development. This argument is less often made explicitly, although as noted above disasters and development have been combined on international policy agendas at times. Particularly in poorer regions, basic development gains - in education, communication, health services, livelihoods - will, all other things being equal, result in households, communities, and economies more capable of coping with disasters. While there will always be disasters that overwhelm any coping capacity, to be somewhat less vulnerable to smaller, 'routine' disasters is almost always a product of higher levels of local scale, appropriate human and economic development. The development benefits of reduced vulnerability may be a less powerful argument in richer countries where poverty and insecure livelihoods are not (or are not seen as) major issues. In many places, however, the combination of the climate adaptation and human development no-regrets arguments linked to disaster preparedness and lowered vulnerability presents a far more powerful case than disasters on their own.

The second important implication of connecting disaster policy to discussions of climate change is that disasters become even more embedded in and connected to other policy sectors and processes, extending the broader trend discussed earlier of disaster policy and emergency management shifting from an isolated to a more open and connected policy sector, profession, and area of operational practice. Also, the slow, punctuated onset of climate change forces thinking about disasters over a longer period of time, where risk or vulnerability reduction strategies need to be considered over many decades, in line with projections of climate change and variability. Linking disasters to human development similarly demands a more purposeful, longer term approach where disaster policy must intersect with other concerns more closely. This inevitably makes disaster policy more complicated, difficult, and contested as it comes into closer contact with social and economic concerns, but potentially more effective in reducing vulnerability. The policy agenda has been reframed.

The literature and practice of 'mainstreaming' disasters is thin, and that dealing with what is known as 'climate policy integration' (CPI) is scant, a product largely of a relatively recent appearance on policy agendas (Kok et al., 2008; Ahmad, 2009; Gupta and van der Grijp, 2010; Fankhauser and Schmidt-Traub, 2011). It can be expected 
that CPI will be a major area of scholarship and policy discussion in coming years, while it is less clear that disaster mainstreaming will be. It is likely that disaster mainstreaming will be largely attended to as a subset of CPI on the adaptation front, and we would argue that disaster researchers and practitioners need to engage energetically with CPI discussions to ensure, firstly, that disaster mainstreaming is given due attention and, second, that CPI discussions can benefit from the longer history of scholarship and professional and policy practice available in the disasters field.

Given the recent nature of both CPI and disaster mainstreaming thinking, there are clear benefits in seeking policy sectors where longer and larger bodies of knowledge may exist. A leading candidate is environmental policy integration (EPI), which as part of the sustainable development agenda has been the subject of research and policy attention since the 1990 s and therefore may inform CPI and disasters (Ahmad, 2009). While mostly derived from Western and especially northern European contexts, EPI has a considerable literature and body of evaluated policy experiments (e.g., Lenschow, 2002; Ross and Dovers, 2008; Jordan and Lenschow, 2010). Environmental policy shares with disasters the attribute of existing mainly to address the negative consequences of actions (or inactions) in other policy sectors (for example, land use planning, industrial safety and control). More broadly, the challenge of 'horizontal' policy integration (whole-ofgovernment, joined-up-government) is a long standing issue in public policy and institutional analysis (Peters, 1998) and there is considerable scope for CPI and disaster mainstreaming to explore lessons and institutional ideas across other policy sectors.

\subsection{The future: disaster policy in broader context}

The preceding discussion has noted a broadening agenda and widening of the scope of research and policy focus in disaster policy and emergency management, and suggests that this evolution needs to continue for better disaster preparedness, but also for climate change adaptation and basic human development. However, the mainstreaming of disaster policy and integration of climate adaptation into other policy sectors is a new and difficult task. This final section mounts an argument for how these too-often disparate issues can be connected. Both disasters and adaptation are embedded in a complex web of social, environmental, and economic concerns, and there is only one policy agenda that seeks to integrate social, environment, and economic concerns: sustainable development.

First promoted by the World Commission on Environment and Development (WCED, 1987), sustainable development was articulated as a global and national policy agenda at the United Nations Conference on Environment and Development in Rio de Janeiro in 1992, the 'Rio Earth Summit' (see UN, 1992). That meeting produced the wide-ranging Rio Declaration, and international agreements on forests, biodiversity, and, importantly, the UN Framework Convention on Climate Change. The overarching goal of sustainable development brings onto one policy and societal agenda a wide range of "environmental' issues (forests, oceans, climate, biodiversity, water and rivers, etc.) with issues of poverty, human development, technology, and security. These issues are accepted as interrelated, and requiring integration of long and short term perspectives, and of social, environmental, and economic imperatives in decision-making.

The progress with the policy agenda of sustainable development has been mixed, and was reviewed - and strongly reaffirmed at an aspirational level - at the 2012 'Rio +20' UN Conference on Sustainable Development (UN, 2012). This complex story is not within the scope of the present discussion, but one point is important. Impatience with progress with sustainable development, and critiques of the size and complexity of the policy agenda, overlook two important points. First, sustainable development is a higher order social goal, akin to equity, the rule of law, democracy, or justice. Such goals are not quickly advanced or arguably ever finally resolved. Second, it is inarguable that the constituent issues of sustainable development, social, environmental, and economic, including disasters, are closely intertwined in both cause and effect and thus require policy attention to be alert to and act in accordance with this interdependency. As difficult, vague, or slow as understanding of and progress with sustainable development may be, there is no evident alternative framing of this range of inter-related issues available. As Harrison (1992) argued, and not unbelievably so, sustainable development is the 'universally agreed goal of human progress'. Thus, we would argue, as we seek to connect disaster policy with related issues of climate change, population change, poverty, vulnerability, land management, urbanisation, and more, sustainable development is the appropriate broader agenda that must be comprehended and utilised.

Relevant to disasters and to the themes of this chapter, between 1992 and 2012, climate change, as only one of the agenda items of sustainable development, has come to dominate arguments over environment and development, and indeed disasters (Ahmad, 2009; Dovers and Hezri, 2010). Somewhat belatedly, the issue of sustainable development entered the main forum of climate change discussions, via the IPCC in its more recent assessment reports (Ahmad, 2009). Moreover, mitigation dominated early debates, with adaptation a more recent issue as it 
became clear that some climate change - and thus its impacts - was locked into the system. This, we believe, was understandable but also unfortunate, as both disasters and sustainable development (and other constituent issues) became separated in research, public discussion, and policy thinking. Opportunities for no- or low-regrets measures, synergies in policy, and lesson drawing across issues and sectors have been less realised than they otherwise might have been.

Sustainable development is a higher order, long term social goal and, despite frustration and difficulties with progress, will not go away as a framework agenda and inevitable imperative. Indeed reviews of progress have confirmed the inevitability of having to focus on an integrated agenda. The formal outcomes of the UN Conference on Sustainable Development (Rio +20) in June 2012 (UN, 2012) made clear the links between climate change and disasters, within the broader context of sustainable development and land management in various paragraphs (111, $135,178,210,280$ ). At paragraphs 186-9, disasters are discussed more specifically:

186. We reaffirm our commitment to the Hyogo Framework for Action 2005-2015: Building the Resilience of Nations and Communities to Disasters and call for States, the United Nations system, the international financial institutions, subregional, regional and international organizations and civil society to accelerate implementation of the Framework and the achievement of its goals ...

187. We recognize the importance of early waming systems as part of effective disaster risk reduction at all levels in order to reduce economic and social damages, including the loss of human life, and in this regard encourage States to integrate such systems into their national disaster risk reduction strategies and plans ... We commit to undertake and strengthen in a timely manner risk assessment and disaster risk reduction instruments.

188. We stress the importance of stronger interlinkages among disaster risk reduction, recovery and long-term development planning, and call for more coordinated and comprehensive strategies that integrate disaster risk reduction and climate change adaptation considerations into public and private investment, decision-making and the planning of humanitarian and development actions, in order to reduce risk, increase resilience and provide a smoother transition between relief, recovery and development. In this regard, we recognize the need to integrate a gender perspective into the design and implementation of all phases of disaster risk management.

189. We call for all relevant stakeholders, including Governments, international, regional and subregional organizations, the private sector and civil society, to take appropriate and effective measures, taking into account the three dimensions of sustainable development, including through strengthening coordination and cooperation to reduce exposure to risk for the protection of people, and infrastructure and other national assets, from the impact of disasters, in line with the Hyogo Framework for Action and any post-2015 framework for disaster risk reduction.
The Rio +20 outcomes are significant in two ways. First, they restate the importance of DRR as a priority of the vast majority of nations and of the international community. This may be viewed as a rhetorical commitment only, but it is a significant statement nonetheless - few international policy statements enjoy such widespread support among countries and fewer again place disasters as central to sustainable development and human futures. Second, and in many ways more significant, is that disasters are rarely mentioned without being closely linked to sustainable development and climate change. These high level policy commitments imply a strong definitional shift that has been evolving for some time, as traced through this chapter: disasters cannot be treated without close reference to other policy sectors.

What prospects, then, for such mainstreaming? The insertion of one imperative into another policy domain is not easy, and it is doubly hard to insert a concern such as disasters across multiple sectors, agencies, and issues. Specialisation in government and in the agencies of government is a very useful thing: specialists are good at their speciality. But they may not be good at comprehending the implications of their decisions for other sectors - the classic example is land use planning which ignores natural hazards and creates vulnerability. Part of the evolution of emergency management we have noted above has been to break oul of the 'expert specialist' mindset and to embrace the perspectives of others, including local communities. Many questions still exist. For example, what is the future of disaster policy and emergency management, where are the other key sectors that create vulnerability, and who can reduce the vulnerability?

There are two risks with pursuing a 'mainstreaming' approach via the sustainable development agenda. The first danger is simply the effort and time involved, which may frustrate those in the disaster policy community and divert effort from core tasks. That we believe is a risk worth taking, as the benefits of a mainstreamed disaster policy agenda are large, as demonstrated by other policy concems which have sought incorporation into other multiple sectors, such as gender equity, occupational health and safety, and environment. The alternative is for those involved in disaster policy and practice to accept a position marginal to policy debates, and to continue to serve as those cleaning up after ill-considered decisions in other domains, such as land use planning, infrastructure development, health services provision, and communications.

The second risk is, as noted above, that only climatedriven hazards will gain attention, at the expense of other hazards. Disasters are not only climate driven, and research, policy, and operational practice need to comprehend, prepare for, and respond to industrial, social, technological, and other hazards as well. That is, however, one benefit of joining disasters more firmly to the agenda of 
sustainable development, alongside issues of technology, pollution, human health, and development and overall governance debates around human-natural system interactions. On one agenda rather than as separate and potentially competing imperatives, breadth and connectivity between issues is an essential consideration. Hence, we argue that the ability of human societies to better understand and respond to disasters requires that disaster policy and emergency management constantly and persistently pursue linkages with climate change adaptation, within the broader agenda of sustainable development. Disasters are important and always will be, but are too quickly forgotten between events and marginalised as political and policy concerns. Climate change is important, topical, and thoroughly linked to disasters. Sustainable development is the only political and policy agenda that forces such connected issues together, however difficult that may be. The combination of the three is potentially powerful, and may serve to provide a much stronger impetus for change - in cultural attitudes and thus policies and institutions terms - than has been the case in the past, or would be the case if the three are considered in isolation.

\section{References}

Ahmad, I. H. (2009). Climate Policy Integration: Towards Operationalization. DESA Working Paper 73. New York: UN Department of Economic and Social Affairs.

Australia (2011) National Strategy for Disaster Resilience. Canberra: Australian Government.

Boyden, S. V. (1987). Western Civilization in Biological Perspective: Patterns in Biohistory. Oxford: Clarendon Press.

CIEL (Centre for International Environmental Law) (2007). Climate Change Program. http://www.ciel.org/Climate/ programclimate.html.

Cockfield, C. and Dovers, S. (2013). The science and policy of climate variability and climate change: intersections and possibilities. In: Drought, Risk Management and Policy: Decision Making under Uncertainty. eds., Botterill, L. and Cockfield, C. Boca Raton: CRC Press, pp. 29-44.

Connor, R. and Dovers, S. (2004). Institutional Change for Sustainable Development. Cheltenham: Edward Elgar.

Cuny, F. C. (1983). Disasters and Development. New York: Oxford University Press.

Dovers, S. (1997). Sustainability: demands on policy. Journal of Public Policy, 16, 303-318.

Dovers, S. (2009). Normalizing adaptation. Global Environmental Change, 19, 4-6.

Dovers, S. R. and Hezri, A. A. (2010). Institutions and policy processes: the means to the ends of adaptation. Wiley Interdisciplinary Reviews: Climate Change, 1, 212-231.

Fankhauser, S. and Schmidt-Traub, G. (2011). From adaptation to climate resistant development: the costs of climate-proofing the Millennium Development Goals. Climate and Development, 3, 94-113.
Gupta, J. and van der Grijp, N. (eds.) (2010). Mainstreaming Climate Change in Development Cooperation. Cambridge: Cambridge University Press.

Handmer, J. and Dovers, S. (2013). Handbook of Disaster Policies and Institutions: Improving Emergency Management and Climate Adaptation, second edn. London: Earthscan.

Harrison, P. (1992). The Third Revolution: Population, Environment, and a Sustainable World. Harmondsworth: Penguin.

IPCC (Intergovemmental Panel on Climate Change) (2011). Special Report on Managing the Risks of Extreme Events and Disasters to Advance Climate Change Adaptation: Summary for Policy Makers. Geneva: IPCC.

IPCC (Intergovernmental Panel on Climate Change) (2012). Special Report on Managing the Risks of Extreme Events and Disasters to Advance Climate Change Adaptation. Geneva: IPCC.

Jordan, A. and Lenschow, A. (2010). Environmental policy integration: a state of the art review. Environmental Policy and Governance, 20, 147-158.

Kok, M., Metz, B., Verhagen, J. and van Rooijen, S. (2008). Integrating climate and development policies: national and international benefits. Climate Policy, 8, 103-118.

Lenschow, A. (ed.) (2002). Environmental Policy Integration: Greening Sectoral Policies in Europe. London: Earthscan.

Mileti, D. (1999). Disasters by Design: A Reassessment of Natural Hazards in the United States. Washington, DC: Joseph Henry Press.

Mitchell, J. K. (1999). Crucibles of Disaster; Megacities. Tokyo: United Nations University.

Pelling, M. (2003). The Vulnerability of Cities: Natural Disasters and Social Resilience. London: Earthscan.

Perrow, C. (1984). Normal Accidents: Living with High-Risk Technologies. New York: Basic Books.

Peters, G. (1998). Managing horizontal government. Public Administration, 76, 295-311.

Productivity Commission (2012). Barriers to Effective Climate Change Adaptation (Draft Report) April 2012. Canberra: Productivity Commission.

Quarantelli, E. L. (ed.) (1998). What is a Disaster? Perspectives on the Question. London: Routledge.

Ross, A. and Dovers, S. (2008). Making the harder yards: environmental policy integration in Australia. Australian Joumal of Public Administration, 67, 245-60.

Standards Australia (2004). Australian Standard/New Zealand Standard 4360-2004: Risk Management. Sydney: Standards

Stern N. (2006). The Economics of Climate Change: the Stern Review. Cambridge: Cambridge University Press.

Turner, B. (1978). Man-Made Disasters. London: Wykeham.

UN (United Nations) (1992). Agenda 21: The Programme of Action from Rio. New York: UN.

UN (United Nations) (2012). The Future We Want: Rio +20 United Nations Conference on Sustainable Development, Outcomes of the Conference. A/CONF.216/L.1. New York: UN.

WCED (World Commission on Environment and Development) (1987). Our Common Future. Oxford: Oxford University Press.

White, G. (1945). Human Adjustment to Floods. Chicago, IL: University of Chicago Press. 